\title{
Idiopathic recurrent stupor
}

INSERM

\section{Source}

INSERM. (1999). Orphanet: an online rare disease and orphan drug data base. Idiopathic recurrent stupor. ORPHA:276174

Idiopathic recurrent stupor is a rare neurologic disease characterized by unpredictable, transient and spontaneous unresponsiveness lasting from hours to days, with a frequency of three to seven attacks per year, in the absence of readily discernible toxic, metabolic or structural causes. 